Int. J. Electrochem. Sci., 13 (2018) 4923 - 4932

\title{
An amplified sensor based on improved carbon paste electrode with 1,3-Dipropylimidazolium Bromide and MgO/SWCNTs Nanocomposite for tradamol determination
}

\author{
Firuzeh Hosseini $^{1}$, Mahmoud Ebrahimi ${ }^{1, *}$ and Hassan Karimi-Maleh ${ }^{2}$ \\ ${ }^{1}$ Department of Chemistry, Mashhad Branch, Islamic Azad University, Mashhad, Iran \\ ${ }^{2}$ Department of Chemical Engineering, Laboratory of Nanotechnology, Quchan University of \\ Technology, Quchan, Iran \\ *E-mail: ebrachem2007@yahoo.com;
}

doi: $10.20964 / 2018.05 .12$

Received: 6 January 2018 / Accepted: 26 February 2018 / Published: 10 April 2018

The electrochemical behavior of tramadol at carbon paste electrode amplified with the 1,3dipropylimidazolium bromide and $\mathrm{MgO} / \mathrm{SWCNTs}$ nanocomposite (1,3-DI-Br/MgO/SWCNTs/CPE) has been studied in aqueous solutions. The oxidation of tramadol at the $\mathrm{pH}$ range of 6.0-9.0 has been investigated. At the optimum condition of $\mathrm{pH} 8.0$, the tramadol shows an irreversible signal at $0.81 \mathrm{~V}$. The scan rate investigation confirms a diffusion process for the electro-oxidation of tramadol at a surface of 1,3-DI-Br/MgO/SWCNTs/CPE. Square wave voltammetric investigation shows a linear relation between the tramadol current and concentration within the range of $0.05-280 \mu \mathrm{M}$ with a detection limit of $8.0 \mathrm{nM}$. The 1,3-DI-Br/MgO/SWCNTs/CPE has been applied to analyze the tramadol in injection and urine samples.

Keywords: Tramadol, MgO/SWCNTs nanocomposite, 1,3-dipropylimidazolium bromide, Electrochemical sensor

\section{FULL TEXT}

(C) 2018 The Authors. Published by ESG (www.electrochemsci.org). This article is an open access article distributed under the terms and conditions of the Creative Commons Attribution license (http://creativecommons.org/licenses/by/4.0/). 